\title{
An innovative mental health outreach program in Southern Sri Lanka: Successes and Lessons learnt
}

\author{
Chandrasiri P. A. A. ${ }^{1}$, De Silva P. V. ${ }^{2}$, Karunarathne A. D. U. ${ }^{3}$, Ruban R. ${ }^{4}$, Madiwaka M. W. M. K. ${ }^{5}$, \\ Suveendran $\mathbf{T}^{6}{ }^{6}$
}

${ }^{1}$ Post Graduate Institute of Medicine, University of Colombo, Matara, Sri Lanka

${ }^{2}$ Department of Community Medicine, Faculty of Medicine, University of Ruhuna, Matara ,Sri Lanka

${ }^{3}$ Office of the Regional Director of Health Services, Hambantota, Sri Lanka

${ }^{4}$ Teaching Hospital, Karapitiya, Sri Lanka

${ }^{5}$ General Hospital, Hambantota, Sri Lanka

${ }^{6}$ Country Office of World Health Organization, Colombo, Sri Lanka

\section{Email address:}

amilachan@yahoo.com (Chandrasiri P. A. A.), pvijithadesilva@yahoo.com (De Silva P. V.), karunarathna71@yahoo.co.in (Karunarathne A. D. U.), karunarathna71@yahoo.co.in (Madiwaka M. W. M. K.)

\section{To cite this article:}

Chandrasiri P. A. A., De Silva P. V., Karunarathne A. D. U., Ruban R., Madiwaka M. W. M. K., Suveendran T.. An Innovative Mental Health Outreach Program in Southern Sri Lanka: Successes and Lessons Learnt. European Journal of Preventive Medicine. Special Issue: New Frontiers of Public Health from the Pearl of Indian Ocean, Sri Lanka. Vol. 3, No. 2-1, 2015, pp. 24-30. doi: 10.11648/j.ejpm.s.2015030201.15

\begin{abstract}
Psychiatric illnesses has emerged as an important disease category as prevalence of mental disorders is being rising sharply. The disease burden due to mental illnesses is rising in Sri Lanka as well. Provision of care for those who are psychiatrically ill poses a significant challenge to health care systems. In this circumstances a community based our reach program becomes an important and effective strategy to improve psychiatric services provided for patients. Community support officers (CSO) program was launched in 2006 in district of Hambantota, Southern Sri Lanka to serve this purpose. Objective of this article is to describe the program in relation to its objectives, initiation, main activities, coordination, technical guidance, funding, monitoring and evaluation. Then we intended to evaluate the success by analyzing performance data and impact made. Finally we critically analyzed the program to discuss strengths and weaknesses in view of providing a guidance to replicate it in other settings. Program documents were reviewed and key informant interviews were done with leading characters of the program. Periodical progress reports and reports on performance review meetings also retrieved. Recruitment of CSO's was done according to set criteria. They were given a special training and skills were developed on identification of common psychiatric illnesses at field level, communication skills and crisis intervention. Lecture discussions and role plays were used as teaching methods and consultant psychiatrists conducted the program. Organizational structure of the program was laid down within the existing administrative framework of primary health care system in the country. Main functions of CSO's were Surveying the community to detect mentally ill people, Guiding and directing patients to seek psychiatric care, following up those patients, Conducting, contributing and participating in community mental health promotion programs. Supervision and monitoring was done at various levels and periodical progress review meetings were held. It was based on inbuilt information system. This program was concluded by the end of 2010. Follow up responsibilities were handed over to primary health staff at $\mathrm{MOH}$ offices. CSO program is a classic example for how community level workers can be empowered and utilized as an effective workforce to deliver mental health services at grass root level where existing system can't penetrate. Carefully planned recruitment criteria, training given by technical experts, linking with existing primary health care system and monitoring done by regional health authorities were responsible for the success of this program.
\end{abstract}

Keywords: Mental Health, Outreach Program, Southern Sri Lanka

\section{Introduction}

Psychiatric illnesses has emerged as an important disease category as prevalence of mental disorders is being rising sharply. It is estimated that approximately 450 million people worldwide have mental health problems(1) which account for 
nearly $6.5 \%$ of world population. Mental disorders are common and often seriously impairing in many countries throughout the world(2). In addition to morbidity the social and economic impact of psychiatric illnesses are immense.

The disease burden due to mental illnesses is rising in Sri Lanka. Suicides which is considered as an end result of untreated psychiatric problems is high in Sri Lanka as the rate is nearly 20 per 100,000 of population(3). Approximately $10 \%$ of population is having depression (4) while $1 \%$ having psychotic illnesses in Sri Lanka according to prevalence studies (5).

Provision of care for those who are psychiatrically ill poses a significant challenge to health care systems worldwide (6). Lack of human resources to provide an adequate care is a major barrier to provide an optimum service. Due to stigma and social isolation, health seeking behavior is poor among those patients. Though they receive adequate management appropriate follow up becomes another challenging task as compliance with management plan is poor among most of psychiatric patients and they default treatments due to many other reasons(7). Amid these reasons it becomes a challenging task to deliver services to those who need. In this circumstances a community based our reach program which address these issues becomes an important and effective strategy to improve psychiatric services provided for patients.

Community Support Officer (CSO) program was launched in mid 2005 as a part of post tsunami health care system rehabilitation activities. But its scope was considered as wider and expected a long lasting impact on improving the mental health of community. The program was coordinated and supervised by Regional Director of Health Services (RDHS), Hambantota and technical guidance was provided by the consultant Psychiatrist at General hospital, Hambantota. Funding was given by World health organization (WHO). When it's conclusion in 2010 it made a significant contribution to improve the psychiatric care provided for patients.

\section{Objectives}

Objective of this article is to describe the program in relation to its objectives, initiation, main activities, coordination, technical guidance, funding, monitoring and evaluation. The situation which led to the initiation of program and formulation of objectives will be discussed. A brief description on major activities carried out under the program will be presented. Programmatic issues including coordination, technical guidance, funding, monitoring and evaluation will also be presented in details.

Then we intended to evaluate the success by analyzing performance data and impact made. Finally we want to critically analyze the program to discuss strengths and weaknesses in view of providing a guidance to replicate it in other settings.

\section{Methodology}

We reviewed the program documents which were extracted from the record room and mental health unit of RDHS office Hambantota in view of obtaining information on initiation, objectives and activity plan of the program. Key informant interviews were done with leading characters who involved into the program. RDHS of Hambantota, Consultant psychiatrist at General hospital, Hambantota, Medical officer- Mental health, mental health coordinator of WHO and few selected CSO's were interviewed. In addition to that few mental health medical officers, Medical officers of health $(\mathrm{MOH})$ and DMO's were also interviewed. Some of the above officials are currently serving in other parts of the country because of transfer system.

We also retrieved and went through periodical progress reports and minutes of review meetings of the program. Statistics on performance of CSO's were obtained from progress reports. Several small group discussions were conducted with group of CSO's and group of patients who received benefits from this program.

\section{Results}

First we intend to describe the program.

1 Origin of the program

The concept of the program was born as part of psychosocial rehabilitation program initiated after tsunami disaster in 2004. Initial discussions were held in 2005 under the guidance of Ministry of health and regional level health authorities and specialist psychiatrists took part in drafting the program objectives and activity plan.

2 Recruitment of CSO's

Priority was given to individuals who have contributed to existing volunteer health promotion programs within community. Experience in other volunteer work at community level and working with non government organizations and special interest in mental health were considered as added qualifications. Age between 18-55, education up to ordinary level, ability to read and write Sinhala were considered as basic qualifications. Ability to handle crisis situations, maintaining confidentiality, work as a team and being responsive and non judgmental, showing empathy and compassion were also assessed. Special attention was given to communication skills.

For selection of supervisory CSO's (SCSO) several other qualifications were considered in addition to above pre requisites. Age between 25-55, study up to advanced level (passing 3 subjects), English literacy, leadership and negotiation skills were assessed.

Applications were called through a news paper advertisement. Names were short listed and called for interviews. Interviews were done at respective $\mathrm{MOH}$ offices and interview panel was consisted of $\mathrm{MOH}$ and $\mathrm{MO}-\mathrm{MH}$ or RDHS. 52 CSO's and 11 SCSO's were recruited.

3 Initial training

All CSO's and SCSO's were given a 12 days training. 
District MO - Mental health coordinated the program and several consultant psychiatrists contributed as resource persons. Main objectives of training were to inculcate skills on identification of common psychiatric illnesses at field level, communication skills and crisis intervention. It was also included a basic knowledge on mental health legislation of Sri Lanka, human rights and health care delivery system of the country. Lecture discussions and role plays were used as teaching methods.

Additional awareness was done on data management. Following initial training a series of in service training programs were conducted from time to time with the guidance of consultant psychiatrist at General hospital, Hambantota. Recruitment and training process is illustrated in figure 1.

4 Organizational structure of the program

Organizational structure of the program was laid down within the existing administrative framework of primary health care system in the country. Organizational structure of CSO program is schematically described in figure 2 .

RDHS, the district level superior of health services was the

\begin{tabular}{|l|}
\hline \multicolumn{1}{|c|}{ Criteria for selection } \\
For CSO's \\
Age $-18-55$ \\
Educational status - Studied upto ordinary level' and \\
ability to read and write Sinhala \\
Work experiences - Volunteer work in community, \\
working with NGO's (areas related to mental health) \\
Additional skills - Ablity to handle crisis situations, \\
ability to work as a team, communication skills, \\
empathy \\
For SCSO's (in addition to above) \\
Age-25-55 \\
Educational status - Studied upto advanced level \\
and ability to read and write English \\
\end{tabular}

administrative head of the program. Overall supervision and monitoring was done by him. Under his guidance MO-MH, district level focal point of mental health services acted as the main coordinator of the program. $\mathrm{MOH}$ had administrative authority at divisional level (there are $11 \mathrm{MOH}$ areas in the district of Hambantota) Direct supervision, provision of technical guidance and administrative work were done by $\mathrm{MOH}$ (who is a medical officer with special training of public health and who has responsibilities in delivering primary health care services at divisional level for approximately 60000 of population) Under the guidance of $\mathrm{MOH}, \mathrm{SCSO}$ leads the team at $\mathrm{MOH}$ level. Compiling and sending reports, attending monthly review meetings, supervision and monitoring of CSO's in the field and coordinating their work at $\mathrm{MOH}$ level were the responsibilities of SCSO. CSO was the grass root level worker in the program. Around 3-5 CSO's were appointed for each $\mathrm{MOH}$ corresponding with the population. One CSO usually covers an area of one Public health inspector, a primary health care officer in the health system.

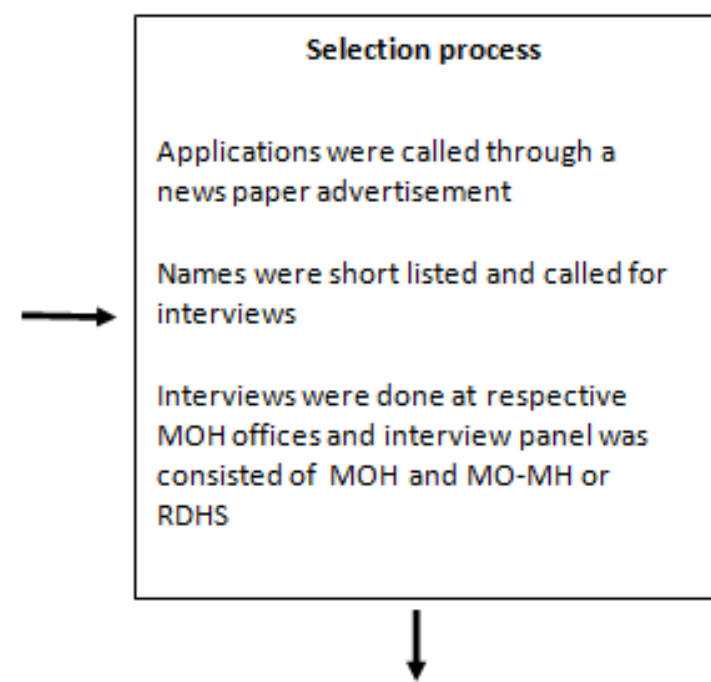

\begin{tabular}{|l|}
\multicolumn{1}{|c|}{ Initial training } \\
Duration-12 days \\
Resources - Consultant psychiatrists \\
(from GH Hambantota and other nearby \\
hospitals) \\
Cordinated by - Medical officer - Mental \\
health (district focal point) \\
Content of training - Skills on \\
identification of common psychiatric \\
illnesses at field level, communication \\
skills and crisis intervention, a basic \\
knowledge on Mental health legislation \\
of Sri Lanka, human rights and health \\
care delivery system of the country. An \\
additional training on data management \\
Teaching methods - Lecture discussions \\
and role plays \\
\hline
\end{tabular}


Table 1. Overall performance of CSO's

\begin{tabular}{llllll}
\hline & $\mathbf{2 0 0 7}$ & $\mathbf{2 0 0 8}$ & $\mathbf{2 0 0 9}$ & $\mathbf{2 0 1 0}$ & Total \\
\hline Number of new home visits & 11024 & 22226 & 18026 & 20425 & 71701 \\
Newly detected cases & 968 & 1065 & 868 & 472 & 3373 \\
Number of patients referred & 892 & 972 & 675 & 386 & 2925 \\
Number attended for treatments out of referred & 601 & 616 & 429 & 198 & 1844 \\
Number of follow up visits & 228 & 624 & 620 & 1062 & 2534 \\
Number of School visited & 52 & 64 & 47 & 71 & 234 \\
\hline
\end{tabular}

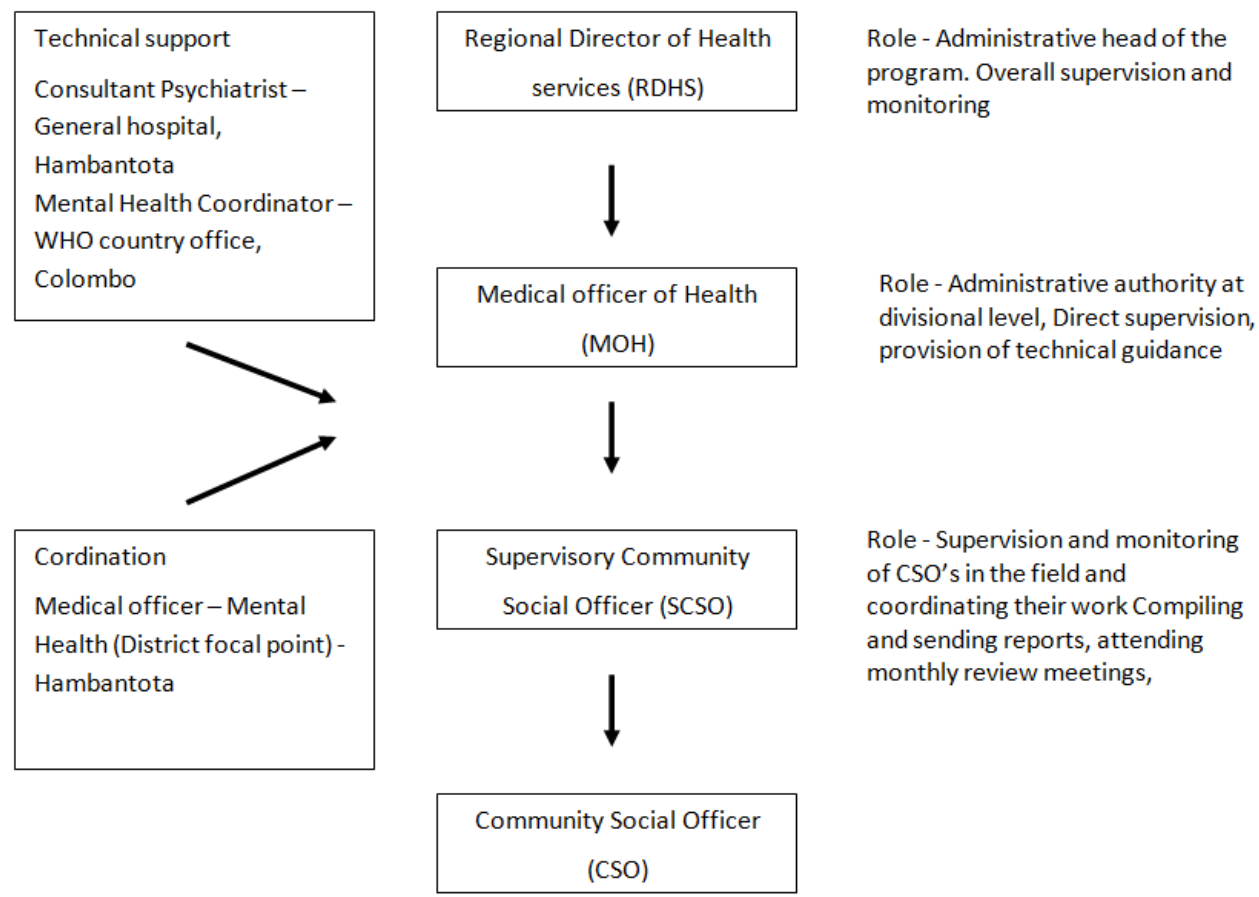

Figure 2. Organizational structure of CSO program

Consultant psychiatrist at General hospital, Hambantota provided the overall technical guidance for the program. From the initial training the consultant provided continues technical support at various stages. In service training programs were conducted by his team and he also attended the monthly review meetings. Mental health coordinator at WHO country office also contributed by providing technical expertise and coordinating overall monitoring and supervision.

5 Funding and payment of allowances

The program was funded by WHO. CSO's were given a monthly allowance. Funds were transferred to RDHS and payment of allowances were done by $\mathrm{MOH}$ office under the supervision of $\mathrm{MOH}$. Upon reception of monthly progress report. RDHS disburse funds to $\mathrm{MOH}$.

As mentioned above the CSO program had a wide range of objectives to uplift the mental health status of people in the district of Hambantota. Under those objectives CSO's carried out following programs.

1 Surveying the community

CSO was supposed to survey the designated geographical area at the beginning of the program by making house to house visits. Target was to cover the full area within 2 years time and report. During the process CSO obtained assistance from Public health midwives, a grass root level primary health care worker who visit each household to provide maternal and child health services.

During the home visit CSO intended to identify mentally ill people in household. As mentioned above they were trained on basic clinical skills in determining major psychiatric disorders. They were also supposed to reinforce proper medical follow up of already diagnosed patients and defaulted patients.

If the patient is not receiving treatments CSO took necessary arrangement to direct them into appropriate medical care. If there is a newly detected case CSO supposed to refer the suspected person first to the $\mathrm{MOH}$ clinic which is happening every Saturday to confirm the diagnosis and then to psychiatric clinic.

2 Guiding and directing patients to seek psychiatric care

Guiding and directing those newly identified patients to psychiatric care is an important duty of CSO's. In line with this program health authorities took measures to extend curative mental health services throughout the district. An outreach clinic program was initiated to cover the entire district. Monthly clinics were conducted in selected divisional hospitals with the participation of consultant psychiatrist. This was planned because distance and financial difficulties were identified as barriers in seeking appropriated medical care. 
CSO's advocated family members on importance of receiving psychiatric care. Elimination of stigma and curability of the disease condition with proper medical treatment were stressed in those discussions. CSO's practically assisted patients in reaching hospitals too. Three wheelers were provided to $\mathrm{MOH}$ offices with WHO funds as a part of this program and CSO's were eligible to use those vehicles under the permission of $\mathrm{MOH}$ to transport patients.

They also convinced defaulted patients to restart treatment. During home visits and meeting with family members they explored the reasons for defaults and helped in solving those problems. Importance of continuing treatment was also stressed.

3 Follow up

Follow up of those patients was an essential component of CSO's duties. They made subsequent follow up visits after starting treatment. They checked clinic records and ensure compliance with treatments. Explaining the importance of adherence with pharmacological management, giving information on side effects was also done. They motivated family members to take the patient properly on due clinic dates.

4 Assisting outreach clinics

CSO's are supposed to be present and assist at $\mathrm{MOH}$ clinics and above mentioned outreach clinics. They helped the medical staff in seeing patients. Introduction of patients and offering practical help were also done.

5 Conducting, contributing and participating in community mental health promotion programs

CSO's actively participated in conducting health promotion programs in community under the guidance of MOH's. As they have links with existing social network in the community their contribution were really helpful in planning and implementing mental health programs in the community.

6 Contributing into mental health programs in schools

CSO's are supposed to visit schools and conduct mental health promotion activities under the supervision of area $\mathrm{MOH}$. It was linked with existing school health promotion program which is conducted by $\mathrm{MOH}$ as a routine public health activity. CSO's participated into these programs and conducted various activities like programs to improve mental well being of adolescents, addressing specific psychological issues and detecting and referring of children with psychiatric morbidities.

7 Supervision and monitoring

Supervision and monitoring was done at various levels. It was based on inbuilt information system. SCSO's were supposed to supervise filed work of CSO's. MOH had the authority for overall supervision and monitoring at divisional level. Each CSO was supposed to submit a monthly performance report according to a format given. This report covered many aspects of service provision. Data were collected at MOH level first and then forwarded to RDHS office. All data were analyzed and interpreted there under the observation of MO-MH. There were monthly progress review meetings which were chaired by RDHS and all
SCSO's took part. Prevailing issues, challenges and measures to overcome were discussed. There were comprehensive reviews with the participation of all CSO's organized once in every 3 months. RDHS was also supposed to send a consolidated monthly report to WHO country office.

Overall performance of CSO's as reported in the information system is presented in table 1 .

Total number of new home visits made in each year is presented. Number of follow up visits are mentioned separately. It is less in first year but gradually increased as program progressed. Then number of newly detected cases, number of referrals and number of patient attended out of referred are also presented. In addition to that performance related to community involvement also mentioned. Number of health promotion programs in community and number of school based mental health programs conducted by CSO's are mentioned.

This program was concluded by the end of 2010. Follow up responsibilities were handed over to primary health staff at $\mathrm{MOH}$ offices. Many CSO's were absorbed into government health system as permanent employers. Some of them were posted to psychiatric in patient units in district as social workers. Though official documentations are not available most of CSO's continued to contribute to various mental health promotion programs conducted at $\mathrm{MOH}$ and district level.

\section{Discussion}

CSO program can be regarded as a success story on how locally available human resources can be utilized to deliver psychiatric care services at grass root level and improve services provided to psychiatrically ill people amid various prevailing challenges. It also shows how the proper technical guidance provided at various levels and continuous monitoring and supervision lead to better outcome in a public health program.

There are an estimated number of 135,500 households in district of Hambantota by the year 2010 and $52.9 \%$ were covered throughout the program. Total number of 3373 new cases were detected over 4 years and it reaches $0.6 \%$ of total population in 2010. It's less than the estimated figure of undetected psychiatric patients as revealed by community based prevalence studies. Number of patients referred is 2925 in total. Gap of $13.3 \%$ is not explained. But out of total number of referred $63.0 \%$ attended the clinic. It's a commendable figure and indicates the success of program. Increase number of follow up visits shows widening of client base and continuation of follow up.

There are 319 schools in Hambantota district by 2010 and nearly $15-20 \%$ was covered in each year. Exact information about what activities performed were not available. There were significant number of community mental health promotion programs were also conducted.

We can identify several key factors which was responsible for the success of the program.

1 Laying down the organizational structure of the 
program on existing health care structure of the country Success of any newly implemented public health program depends on how well it can be integrated to the existing health care delivery system of country. Program designers considered this fact well in the planning stage of CSO program. Organizational structure of the program was built within the public health structure (RDHS and $\mathrm{MOH}$ structure) as described above. Therefore it was no need to setup a new administrative structure for this program and the existing infrastructure were used. Administrative and supervisory capabilities of RDHS and $\mathrm{MOH}$ offices was a significant strength.

Existing curative care set up of the country was used to cater patients who were referred through this program. On the other hand CSO program became a stimulant to enhance curative services as well. An outreach clinic program was launched in line with this to deliver specialist services.

2 Well planned and focused training given to CSOs by technical experts

Technical expertise that planned and conducted the initial training of CSO's made a wonderful contribution for the success of the program. Technical competency and dedication of trainers helped in transforming those newly recruited CSO's into capable group of health care workers with adequate knowledge and skills to perform their desired job.Continuous contribution received from consultant psychiatrist at GH Hambantota helped in further enhancing capabilities of CSO's through in service training.

3 Recruitment of highly motivated and committed group as CSO's

Skills and capabilities of CSO's were a key factor for the success of this program. As mentioned in the methodology a well formed selection criteria was followed in recruiting them. High level of commitment to work and ability to work as a team were shown by most of them.

As described above some of CSO's worked as volunteers in various health programs before. Because of that they had experiences in working with public health system of the country. Being working with community for a long time most of them were integrated well with existing social networks and highly accepted within communities. These factors were helpful in reaching for grass root level.

4 Well organized and comprehensive information system

A comprehensive and well planned information system was laid down to monitor performance of the program. Performance of each CSO was continuously tracked in many aspects. Special attention was paid on ensuring timeliness, completeness and accuracy of data. SCSO's and MOH were supposed to summate, analyze, interpret and take necessary actions at divisional level. Same procedure was done at RDHS level by MO-MH and corrective actions were taken accordingly. This was linked with progress review process.

5 Continuous progress review mechanism

As described above a comprehensive progress review process contributed to the success of program. Continuity and technical support provided by the consultant psychiatrist for the review process were key factors.

\section{Limitations and constraints}

Following limitations and constraints were identified in the program

1 Lack of human resources to provide adequate psychiatric services in curative sector

Lack of specialist psychiatrists and other doctors who specially trained in psychiatry was a significant barrier. Consultants were placed only in General hospital, Hambantota and other trained doctors were stationed in only 2 other institutes. The outreach clinic program as described above brought some solution to the problem. Lack of other staff categories like psychiatric nursing officers, psychiatric social workers, occupational therapists also became a hindrance in providing optimal service.

2 Lack of mechanisms to offer financial help for patients and families

Lack of financial capabilities prevented some patients receiving adequate care. In CSO program there were no any mechanism put in place to offer financial support for deserving people.

3 Stigma and discrimination towards mentally ill people

Though CSO program make a significant impact to change the view point of people to a certain degree the long standing stigma which is deeply rooted in society became a significant barrier in certain occasions.

\section{Transport of CSO's and patients}

Though $\mathrm{MOH}$ office provided limited transport facilities (by the three wheelers as mentioned above) transportation of patients to clinics became a challenging task. Poor economic status and living in remote areas with inadequate public transport facilities were constraints.

CSO's also faced the same problem with delivering services. Though transport facilities of $\mathrm{MOH}$ office were utilized in some instances they had to use public transport and spend their own money.

5 Discontinuation of the program

As CSO program was a funded and time bound program it was concluded in 2010. Though there was a mechanism to prevent interruption of continuing care patients might feel difficulty in adjusting to this change.

\section{Conclusion}

CSO program is a classic example for how community level workers can be empowered and utilized as an effective workforce to deliver mental health services at grass root level where existing system can't penetrate. Carefully planned recruitment criteria, training given by technical experts, linking with existing primary health care system and monitoring done by regional health authorities were responsible for the success of this program. These characteristics can be applied to any community level mental health program to obtain a better outcome. More studies are recommended to assess the long term impact of this program. 


\section{Acknowledgement}

Consultant psychiatrists who served in General hospital Hambantota, Dr Rumi Ruban and Dr Manoj Panamulla for the outstanding technical guidance they provided.

\section{References}

[1] WHO. Mental Disorders. World Health Organization; 2014 [cited 2014 05th September 2014]; Available from: http://www.who.int/topics/mental_disorders/en/.

[2] Kessler RC, Gaxiola SA, Alonso J. The global burden of mental disorders: An update from the WHO World Mental Health (WMH) Surveys. National Institute of Health2011. p. 23-33.

[3] Sri Lanka Sumithrayo. Statistics and Data of Suicides. Sri
Lanka Sumithrayo; 2010 [updated 05th September 2011; cited 2011 05th September ]; Available from: http://srilankasumithrayo.org/statistics-a-data.

[4] Harriet AB, Sisira HS, Yulia K, Glozier N, Sumathipala A. Epidemiology and symptomatology of depression in Sri Lanka: A cross-sectional population-based survey in Colombo District. Journal of Affected Disorders 2010:188-96.

[5] Jenkins R, Mendis J, Cooray S, Cooray M. Integration of mental health into primary care in Sri Lanka. World Psychiatry. 2010.

[6] Sadock B, Sadock V, editors. Kaplan and Sadock's Synopsis of Psychiatry: Behavioral Sciences/Clinical Psychiatry. 10 ed: Lippincott,Williams and wilkins 2007.

[7] Regional Director of Health Services Hambantota. Annual Mental Health Report 2010. 2010:4. 